\title{
Guided bone regeneration with local zoledronic acid and titanium barrier: An experimental study
}

\author{
SERKAN DUNDAR $^{1}$, CEM OZGUR $^{2}$, FERHAN YAMAN $^{3}$, OMER CAKMAK $^{4}$, ARIF SAYBAK $^{5}$, \\ IBRAHIM HANIFI OZERCAN $^{6}$, HILAL ALAN $^{7}$, GOKHAN ARTAS $^{6}$ and ONUR NACAKGEDIGI ${ }^{8}$ \\ ${ }^{1}$ Department of Periodontology, Faculty of Dentistry, Firat University, Elazı $\breve{g}, 23119$ Elazı $\breve{g}$; \\ ${ }^{2}$ Department of Oral Maxillofacial Surgery, Corlu Dental and Oral Health Centre, Ministry of Health, Tekirda $\breve{g}$, \\ 59850 Tekirdağ ${ }^{3}$ Department of Oral Maxillofacial Surgery, Faculty of Dentistry, Dicle University, \\ Diyarbakır, 21280 Diyarbakır; ${ }^{4}$ Department of Periodontology, Faculty of Dentistry, \\ Afyon Kocatepe University, Afyonkarahisar, 03200 Afyon; ${ }^{5}$ Private Practice, Adana, 01220 Adana;

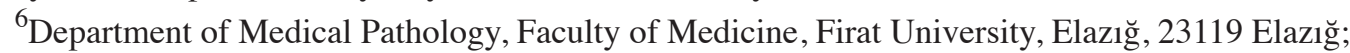 \\ ${ }^{7}$ Department of Oral Maxillofacial Surgery, Faculty of Dentistry, Inonu University, Malatya, 44280 Malatya; \\ ${ }^{8}$ Department of Restorative Dentistry, Dicle University, Diyarbakır, 21280 Diyarbakır, Turkey
}

Received December 23, 2015; Accepted May 27, 2016

DOI: $10.3892 / \mathrm{etm} .2016 .3598$

\begin{abstract}
The aim of this study was to evaluate the effects on new bone formation of autogenous blood alone or in combination with zoledronic acid (ZA), a $\beta$-tricalcium phosphate $(\beta$-TCP) graft or ZA plus a $\beta$-TCP graft placed under titanium barriers. For this purpose, eight adult male New Zealand white rabbits were used in the study, each with four titanium barriers fixed around four sets of nine holes drilled in the calvarial bones. The study included four groups, each containing 2 rabbits. In the autogenous blood (AB group), only autogeneous blood was placed under the titanium barriers. The three experimental groups were the $\mathrm{AB}+\mathrm{ZA}$ group, with autogenous blood plus $\mathrm{ZA}$, the $\mathrm{AB}+\beta-\mathrm{TCP}$ group, with autogeneous blood plus a $\beta$-TCP graft, and the $A B+\beta-T C P+Z A$ group, with autogeneous blood plus a $\beta$-TCP graft and ZA mixture under the titanium barriers. The animals were sacrificed after 3 months. The amounts of new bone formation identified histomorphometrically were found to be higher after 3 months than at the time of surgery in all groups. The differences between the groups were examined with histomorphometric analysis, and statistically significant differences were identified at the end of the 3 months. The bone formation rate in the $\mathrm{AB}+\beta-\mathrm{TCP}+\mathrm{ZA}$ group was determined to be significantly higher than that in the other groups $(\mathrm{P}<0.05)$. In the $\mathrm{AB}+\mathrm{ZA}$ and $\mathrm{AB}+\beta-\mathrm{TCP}$ groups, the bone formation rate was determined to be significantly
\end{abstract}

Correspondence to: Dr Serkan Dundar, Department of Periodontology, Faculty of Dentistry, Firat University, Campus,

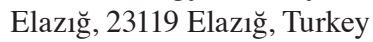

E-mail: dtserkandundar@gmail.com; sdundar@firat.edu.tr

Key words: guided bone regeneration, zoledronic acid, titanium barrier, rabbit calvarium higher than that in the $\mathrm{AB}$ group $(\mathrm{P}<0.05)$. No statistically significant difference in bone formation rate was observed between the $\mathrm{AB}+\beta-\mathrm{TCP}$ and $\mathrm{AB}+\mathrm{ZA}$ groups. Local $\mathrm{ZA}$ used with autogeneous blood and/or graft material appears to be a more effective method than the use of autogeneous blood or graft alone in bone augmentation executed with a titanium barrier.

\section{Introduction}

The guided bone regeneration (GBR) technique is used for bone tissue reparation in dentistry. The basic concept in GBR is the placement of a barrier to preserve the blood that is formed and create a closed area around the bone defect, hence facilitating the activation of osteoblasts. In general, it has been accepted that this kind of barrier must be pervious to enable the spreading of nutrients to the regenerated bone (1-3).

In bone tissue reparation, the use of autogenous bone grafts is the gold standard. Autogeneous bone grafts have osteoinductive and osteoconductive properties. Additionally, autogeneous grafts contain stem cells and growth factors and do not create any immunological reaction (3). However, the requirement for a second surgical area, restricted amount of bone graft and graft resorption have led to the development of various graft materials and treatment methods for bone augmentation $(3,4)$. Human-derived bone grafts (allografts) are less osteogenic, more immunogenic and have a greater rate of resorption than autogeneous bone grafts, with a potential risk of disease transmission (e.g., hepatitis and HIV-AIDS). As a result of these limitations, synthetic bone grafts (alloplasts) have been developed. Ideally, alloplastic graft materials should be biocompatible with host tissues, non-antigenic and non-inflammatory. Calcium phosphate ceramics, such as $\beta$-tricalcium phosphate $(\beta$-TCP), have been shown to induce bone regeneration in experimental animal models, and are suggested to have high 
stabiility and osteogenic potential compared with autologous bone grafts $(3,5)$. Due to their composition and structure, bioceramic synthetic bone grafts degrade and are progressively replaced by bone (5).

GBR with a rigid titanium barrier has been used successfully for enhancing bone tissue in certain in vivo studies (3,6-9). In this method, a rigid titanium barrier is installed under the periosteum to mineralize the underlying blood clot for increase bone height. There have been a few studies concerning bone augmentation using autogeneous blood under titanium rigid barriers. In these studies the researchers aimed to increase bone formation beneath the rigid titanium barrier. They reported that cortical bone perforation allowed the movement of angiogenic and osteoblastic cells into the closed space (3,6-9).

Biphosphonates (BPs) are used to prevent and treat increased bone resorption in skeletal diseases $(10,11)$. The influence of BPs on bone healing and the interaction between bone and implant have been investigated $(12,13)$. Throughout the bone repair process, BPs have been shown to induce an anti-osteoclastic effect and, thus, a relatively osteoblastic effect $(12,14)$.

BPs have some side effects when used systematically. An initial influenza-like illness, renal failure and osteonecrosis have been documented in the literature when used systematically $(12,14)$.

Zoledronic acid (ZA) is the strongest of the BPs in clinical use. A single dose of ZA, administered intraoperatively, has been shown to have positive effects on various models of bone repair and healing $(15,16)$. In the present study the aim was to evaluate the effect of locally administered ZA with autogeneous blood on new bone regeneration with or without a $\beta$-TCP graft under a rigid titanium barrier in rabbit calvarium.

\section{Materials and methods}

Animal care and ethics. Experimental applications in this study were authorized by the Animal Experimental Ethics Committee of Firat University (Elazı $\breve{g}$, Turkey). The rabbits were kept and treated according to advice of the Declaration of Helsinki. Rabbits were kept in standard cages during the experimental period $\left(21-23^{\circ} \mathrm{C}, 50-65 \%\right.$ humidity, $1 \mathrm{~atm}$ and a 12-h light-12-h dark cycle). Rabbits received a balanced standard ration diet and drinking water ad libitum during the experimental period.

Experimental protocols and surgical procedure. Eight New Zealand white male rabbits (weight, 3-3.5 kg; age, 0.5-1 year) were used in the study. The rabbits were obtained from the Experimental Research Center of Firat University. The 8 rabbits were divided four groups, each containing two animals: Autogeneous blood (AB) group; $A B+Z A$ group; $\mathrm{AB}+\beta-\mathrm{TCP}$-bone graft group; and $\mathrm{AB}+\beta-\mathrm{TCP}-$ bone graft $+\mathrm{ZA}$ group. Prior to all surgical procedures, rigid dome-shaped pure titanium barriers were constructed (Elektron Medikal, Ankara, Turkey). These rigid titanium barriers had a hole in the top for which a Teflon cap was made. The rigid barriers were cleaned and then sterilized prior to use (Fig. 1).

Surgical operations were conducted in sterile conditions. General anesthesia was established using $10 \mathrm{mg} / \mathrm{kg}$ xylazine $\left(\right.$ Rompun $^{\circledR}$ ) and $40 \mathrm{mg} / \mathrm{kg}$ ketamine. Following general anesthesia and prior to surgery the skull skin was shaved. An incision in the skin of the skull was made over the linea media. A periosteal elevator was used to lift the flap and periosteum in order to access the parietal and frontal bones of the skull. Nine holes were drilled using a burr of $\sim 1.5 \mathrm{~mm}$ in diameter with saline irrigation to trigger bleeding. In every rabbit calvarium four sets of nine holes were created and four titanium barriers (one for each set) were used (Fig. 1). The edges of the barriers were bonded to the bone tissue with N-butyl-2-cyanoacrylate (Histoacryl ${ }^{\circledR}$; B.Braun, Melsungen, Germany). In the AB group, decortication of the cortical layers was executed on the parietal and frontal bones and autogeneous blood was taken from the rabbit's ear artery and injected into the titanium barrier through the holes until the barrier was fully filled. In the $\mathrm{AB}+\mathrm{ZA}$ group, blood taken from rabbit's ear artery was mixed with ZA ( $2 \mathrm{mg} \mathrm{ZA} / \mathrm{ml}$ autogeneous blood) and was injected into the titanium barriers through the holes in each rabbit calvarium. In the $\mathrm{AB}+\beta-\mathrm{TCP}$ group, $0.5 \mathrm{~cm}^{3} \beta-\mathrm{TCP}$ (IngeniOs; Zimmer Dental GmbH, Ottobrunn, Germany) graft material mixed with $2 \mathrm{ml}$ autogeneous blood from the rabbit's ear artery was used. In the $\mathrm{AB}+\beta-\mathrm{TCP}+\mathrm{ZA}$ group, $0.5 \mathrm{~cm}^{3}$ $\beta$-TCP graft mixed with $2 \mathrm{ml}$ autogeneous blood from rabbit's ear artery and ZA (2 $\mathrm{mg} \mathrm{ZA} / \mathrm{ml}$ autogeneous blood) was used. Graft materials were applied under the titanium barriers through a hole. After this, the holes were closed using the Teflon covers. The skull skin of the rabbits was sutured with 3/0 polyglactin resorbable sutures (Ethicon Vicryl; Johnson \& Johnson, New Brunswick, NJ, USA; Fig. 2). Cefalosporine antibiotic $(50 \mathrm{mg} / \mathrm{kg})$ and analgesic $(4 \mathrm{mg} / \mathrm{kg}$ acetominophen) were injected intramuscularly in all animals 1 day before the surgery, and once in a day for 4 days afterwards. All rabbits were examined for wound cleaning during the healing period for 2 weeks. After healing for 3 months, the rabbits were sacrificed with carbon dioxide. Following sacrifice, a surgical burr attached to an electrical hand motor piece was used to harvest the bone containing the titanium barriers from the rabbits's calvarial bone.

Histological and histomorphometric analysis. The specimens were fixed in $10 \%$ formaldehyde for $72 \mathrm{~h}$ and demineralised in $10 \%$ formic acid; after this, they were dehydrated, embedded in paraffin wax, and sectioned for haematoxylin and eosin staining for light microscopic analysis. Sections $6-\mu \mathrm{m}$ in thickness, corresponding to the bone area, were evaluated by light microscopy. The histological sections were analysed with an Olympus Bx-51 (Olympus Corporation, Tokyo, Japan) light microscope. The presence of inflammatory cell infiltrate, connective tissue, bone graft material resorption, new bone formation, new bone marrow and grafted material were evaluated.

Images of the samples were captured under light using a photo light microscope with an attached digital camera to examine mineralized bone formation. Images from each histological section taken with the attached camera were transferred to a computer and software with an automatic calibration feature (Olympus D71 imaging software system; Olympus Corporation, Tokyo, Japan) was used for histomorphometric analysis of the images. In the histomorphometric analysis of each specimen, the ratio of the regenerated new bone areas $\left(\mu \mathrm{m}^{2}\right)$ to all areas of the barriers (new bone area/saggittal surface barrier area) was calculated with the Dolphin 11.0 
Imaging software and an average value was determined for each sample (3).

Statistical analysis. For the statistical analysis, IBM SPSS Statistics 22 software (IBM SPSS, Armonk, NY, USA) was used. After the 3-month healing period, mean values and standard deviations were calculated. The differences among groups were tested using one-way analysis of variance tests for parameters that showed a normal distribution and Tukey's honest significant difference test was used for the identification of specific groups with significant differences. $\mathrm{P}<0.05$ was considered to indicate a statistically significant difference.

\section{Results}

Histological observations. There were no complications during the surgery. After the application of the titanium barriers, all animals recovered without post-operative signs of infection. In Figs. 3 and 4, histological samples are shown. At 3-months, new bone formation was observed in all groups. A gap was detected between the border of the titanium rigid barrier and the bone in some cases. The bone formation rate in the majority of the histological samples was determined to be much higher in the centre than at the periphery of the tissue. In all groups a bed of dense fibrous connective tissue lined the entire periphery of the tissue. There was active bone formation in all specimens.

Bone formation rates. Bone formation was detected in all groups. There were statistically significant differences in bone formation rate among the groups. The bone formation rate in the $\mathrm{AB}+\beta-\mathrm{TCP}+\mathrm{ZA}$ group was determined to be statistically significantly higher than that in the other groups $(\mathrm{P}<0.05)$. In group $\mathrm{AB}+\mathrm{ZA}$, the bone formation rate was determined to be significantly higher than that in group $\mathrm{AB}(\mathrm{P}<0.05)$. The bone formation rate in group $\mathrm{AB}+\beta-\mathrm{TCP}$ was also determined to be significantly higher than that in group $\mathrm{AB}(\mathrm{P}<0.05)$. No statistically significant difference in bone formation rate was observed between the $\mathrm{AB}+\beta-\mathrm{TCP}$ and $\mathrm{AB}+\mathrm{ZA}$ groups (Table I).

\section{Discussion}

Advanced periodontitis, resective surgery, trauma and tumors are considered to be etiologies of alveolar bone defects (17). Various grafting materials such as autografts, allografts, xenografts and alloplastic graft are used in GBR (17-19). During the GBR procedure, graft materials must be secured in position in the healing period for the treatment of bone defects. Mechanical stresses may cause deformation and disruption of the fibrin clot. This causes tissue regeneration to break down, and fibrous tissue forms. Ensuring the stability of the matrix during healing enables this to be controlled. The use of fixation devices, including GBR membranes, titanium mesh, bone screws or bone tacks can be used to achieve this (20). The placement of a subperiosteal titanium barrier is another method for increasing bone height with the aid of the underlying blood clot for mineralization $(3,9)$. The use of a titanium barrier on the rabbit calvarium can markedly increase the proportion of new bone tissue formation. In

Table I. Bone formation in the four groups.

Groups

$\mathrm{AB}$

$\mathrm{AB}+\mathrm{ZA}$

$\mathrm{AB}+\beta-\mathrm{TCP}$

$\mathrm{AB}+\beta-\mathrm{TCP}+\mathrm{ZA}$

For each group, $\mathrm{n}=8$. SD, standard deviation; $\mathrm{AB}$, autologous blood $\mathrm{ZA}$, zoledronic acid; $\beta$-TCP, $\beta$-tricalcium phosphate. ${ }^{\mathrm{a}} \mathrm{P}<0.001 \mathrm{vs}$. group $\mathrm{AB} ;{ }^{\mathrm{b}} \mathrm{P}<0.05$ vs. group $\mathrm{AB}+\mathrm{ZA} ;{ }^{\mathrm{c}} \mathrm{P}<0.05$ vs. group $\mathrm{AB}+\beta-\mathrm{TCP}$.

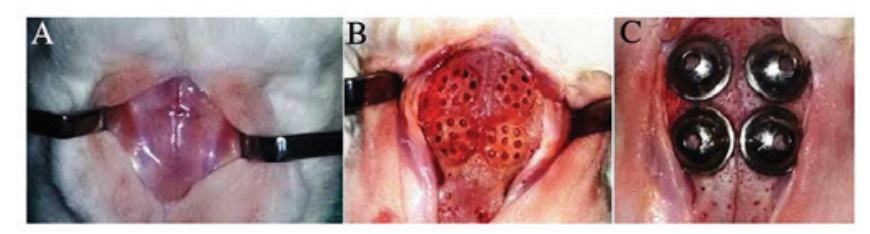

Figure 1. Application of the surgical procedure. (A) A full-thickness flap was made in the anterior-posterior direction in the skin of the skull over the linea media. A periosteal elevator was used to lift the flap and periosteum to access the skull bone. (B) Using a burr with saline irrigation to trigger bleeding, nine holes $1.5 \mathrm{~mm}$ in diameter were drilled. (C) Four titanium barriers were applied.
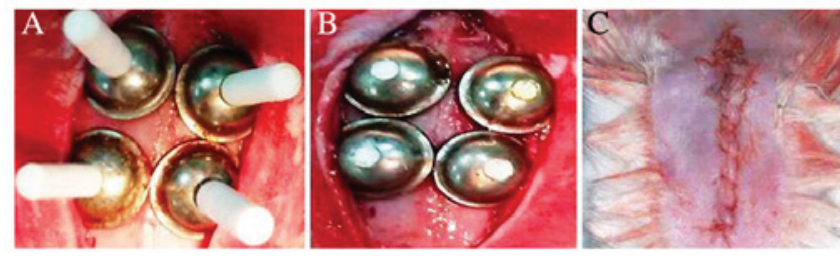

Figure 2. (A) Titanium rigid barriers and Teflon caps after application. The edges of the barriers were bonded to the bone with N-butyl-2-cyanoacrylate, and grafts were applied under the titanium barriers through a hole. (B) The holes were closed with Teflon covers. (C) The skull skin of the rabbits was sutured with resorbable sutures.

earlier studies, the use of a rigid titanium barrier was observed to stabilize bone grafts and blood clots; the titanium barrier inhibits resorption of the graft material $(3,17)$. The results of the present study confirm earlier reports claiming that it is possible to augment the skull bone beyond the original form and that the increase is more substantial if bone grafts are used $(6-8,21,22)$.

Autogenous bone grafts are the gold standard in dentistry for the treatment of bone defects. However, the available amount of autogeneous bone graft is often insufficient and the use of a second surgical area and unpredictable resorption are disadvantages of autogeneous bone graft procedures. For this reason, in the treatment and reconstruction of bone defects the use of synthetic bone graft materials has been considered as a treatment method. Different bone graft materials have been studied in the reconstruction of bone defects in medicine $(17,23)$. $\beta$-TCP is a commonly used synthetic bone graft material in the regeneration of bone defects (17), and has excellent biocompatibility. In contrast to human- and 


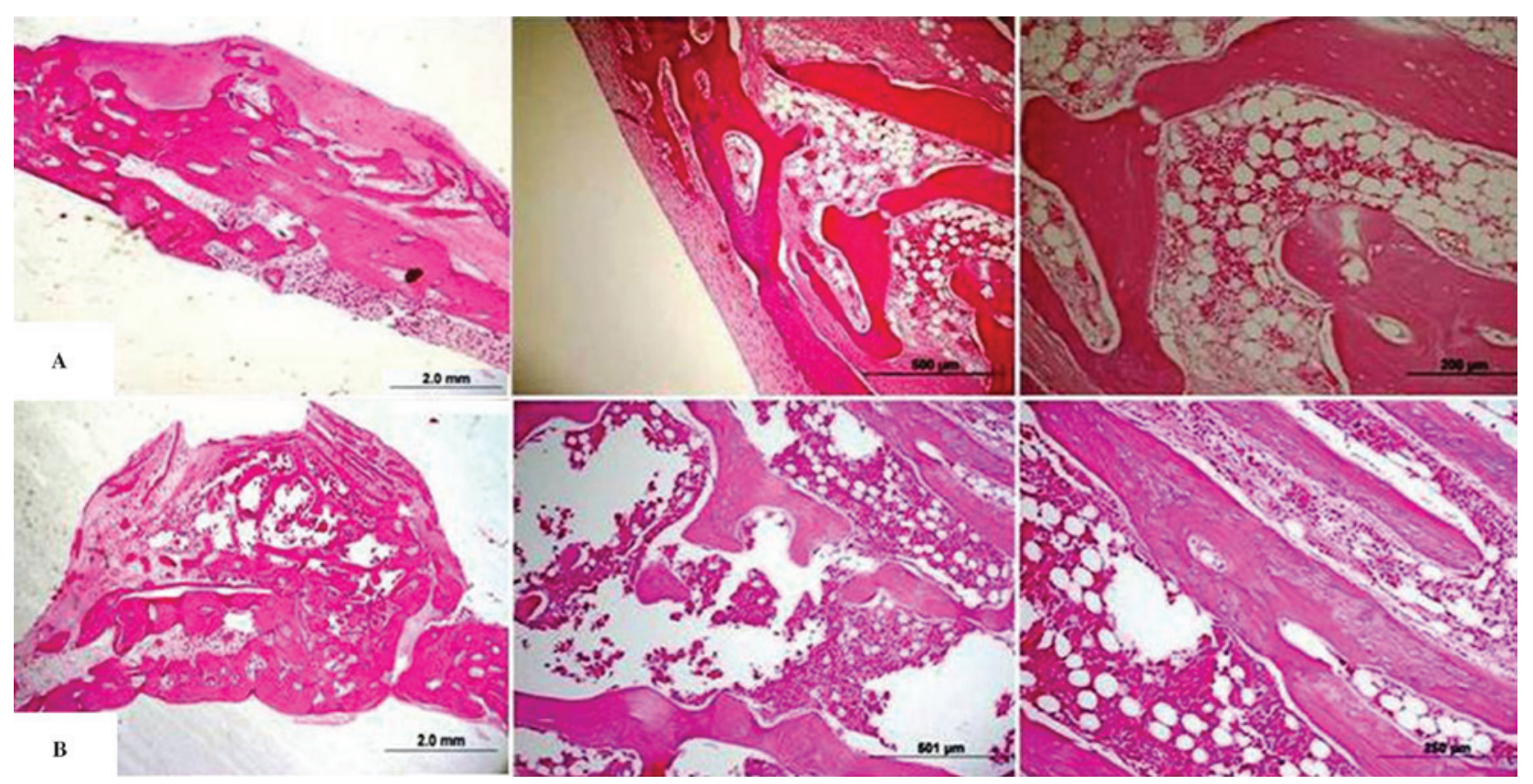

Figure 3. Histopathological images of the (A) AB and (B) AB+ZA groups (hematoxylin and eosin staining). AB, autogenous blood; ZA, zoledronic acid.

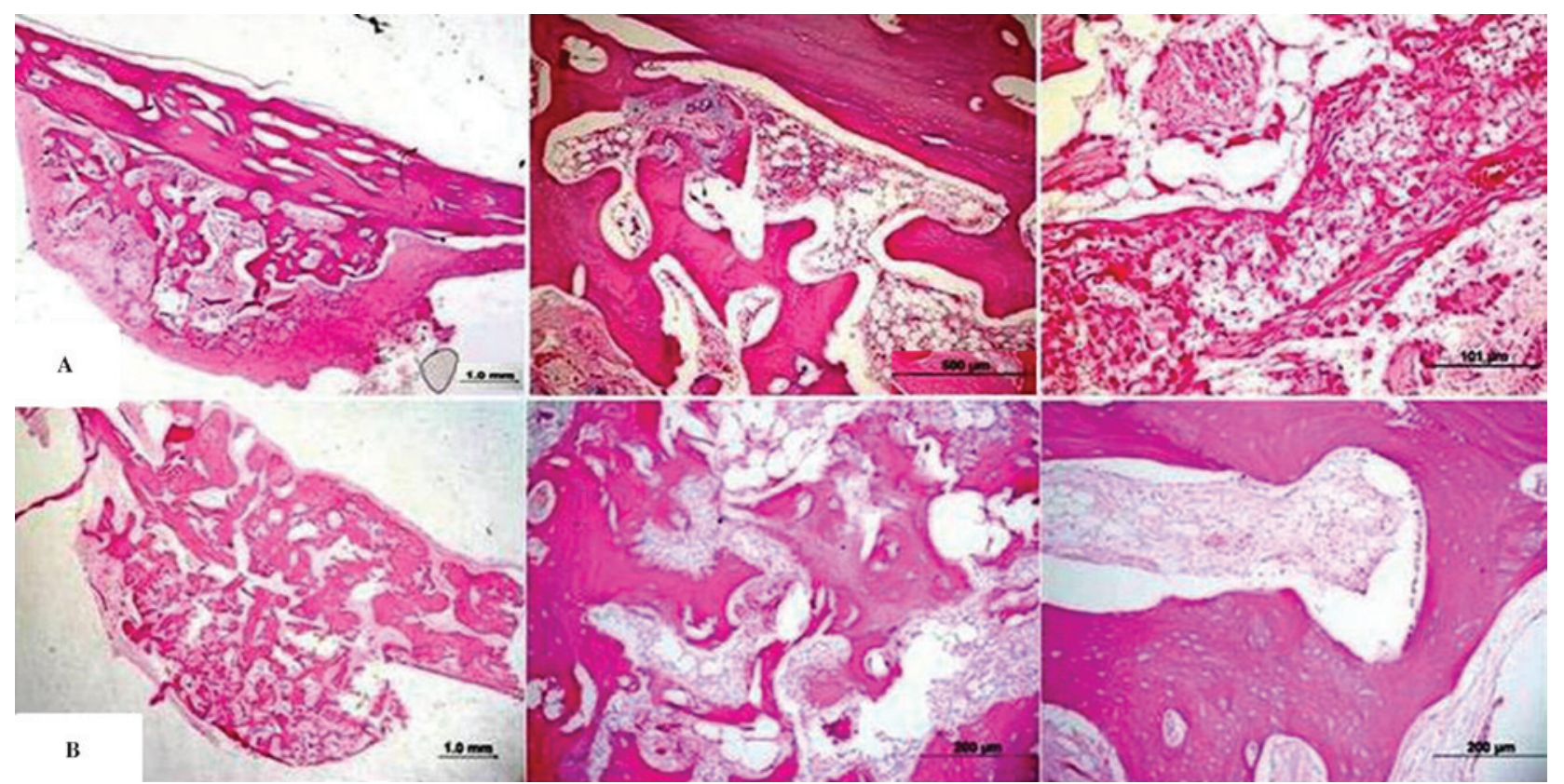

Figure 4. Histopathological images of the (A) $\mathrm{AB}+\beta-\mathrm{TCP}$ and (B) $\mathrm{AB}+\beta-\mathrm{TCP}+\mathrm{ZA}$ groups (hematoxylin and eosin staining). AB, autogenous blood; $\beta-\mathrm{TCP}$, $\beta$-tricalcium phosphate; ZA, zoledronic acid.

animal-derived bone graft materials, the synthetic origin of $\beta$-TCP prevents disease transmission. $\beta$-TCP grafts show good biological suitability and osteoconductive power, as well as a potential capacity for osteoinductivity (23-25). $\beta$-TCP bone grafts are totally resorbed by host bone tissues (23).

There have been only a few studies that have investigated the use of autogenous blood under titanium barriers for bone augmentation $(6,21)$. In these studies, cortical bone perforation was created to allow the migration of angiogenic and osteoblastic cells underneath the membrane to enhance bone formation $(3,26,27)$. Ito et al $(28)$ showed that the use of a titanium barrier membrane can augment the formation of bone beyond the skeletal cover and into areas where no bone was formerly present. Maréchal et al (21) reported that the amount of newly formed bone tissue under the barriers was greater than that detected using other techniques. The results of the present study confirm previous reports that it is possible to amplify skull bone thickness and that new bone formation can occur where no bone was present initially by the use of a titanium barrier. The current study demonstrated that ZA with autogeneous blood and bone graft with ZA plus autogeneous blood exhibits a greater positive effect on new bone tissue formation with use of a titanium cap compared with control groups. 
Formation of new blood vessels and the triggering of active osteoblasts are vital factors in bone tissue repair (26). However, the origin of osteoblastic cells is controversial. Although several authors consider stromal fibroblasts of the bone marrow as the osteoprogenitor cells, others suggest that osteoblasts stem from the capillary system (3). Thus, decortication of the cortical layer of the bone may be beneficial for the accomplishment of tissue regeneration, and may support bleeding and blood clot formation in the wound area, which has been hypothesized to be a vital factor in $\operatorname{GBR}(3,17,26,29)$. Lundgren et al $(29,30)$ found that decortication of the cortical layer of the parietal bone in the rabbit does not result in additional bone formation beyond the skeletal anatomy after a 3-month healing period when compared with a non-decorticated cortical bone plate inside a obscured experimental area. In another study, Min et al (7) conducted a study using rabbits in order to detect whether or not calvarial bone decortication size influences bone augmentation within rigid titanium barriers. The authors detected that decortication size does not affect augmentation; however, this result is not in consistent with the findings of other studies (31-33). For this reason, the same size of decortication cavity was used for all groups in the present study.

BP pretreatment can be useful to prevent graft resorption. In addition, bone cell culture studies have indicated that the use of very low concentrations of BPs increases bone-formation parameters $(15,34)$. Since BPs have a direct action on osteoclasts, it is evident that they may affect bone formation. Osteoclast function can be changed by the production of an osteoclast inhibitory factor excreted by osteoblasts following exposure to BPs. During the bone remodeling process, cells of osteoblastic lineage control the activity of osteoclast cells. BPs increase the proliferation and maturation of osteoblastic cells and reduce apoptosis (15). This information supports the suggestion that BPs have an anabolic effect on bone tissue cells and thereafter promote bone tissue formation. Therefore, the target cells of BPs may include members of the osteoblastic cell family $(15,17)$. BPs have been shown to increase the proliferation of osteoblasts and the biosynthesis of collagen and osteocalcin by bone cells at the cellular level $(5,34)$. In the present study, the histological analysis indicated that the newly formed bone area was increased in all groups at the end of the study. These results appear to confirm similar information in the literature $(5,15-17,34)$. The bone formation rate in the $\mathrm{AB}+\mathrm{ZA}$ group was determined to be statistically significantly higher than that in the $\mathrm{AB}$ group. In addition, no statistically significant difference was determined between the $A B+Z A$ group and the $\mathrm{AB}+\beta-\mathrm{TCP}$ group. These results indicate that autologous blood is effective in GBR; in addition, autologous blood mixed with ZA may provide a greater effect without bone grafts in bone formation (3). Bone formation in the $\mathrm{AB}+\beta-\mathrm{TCP}+\mathrm{ZA}$ group was greater than that in the other three groups, which may indicate that ZA used with bone grafts and autogeneous blood is more effective in osteogenesis. In the present study, we hypothesize that ZA inhibited the resorption of the bone graft, activated osteoblastic cells and increased osteogenesis $(5,17,34)$. Mixing the grafts with BP solution prior to application onto a bone defect appears to be an innocuous method. By treating bone locally with BP, the graft can be prevented from undergoing resorption, without any systemic effects. In an earlier study, it was detected that the local application of BP solution onto an allograft protected the graft from resorption (5). In the present study, pre-treatment of the bone graft with ZA inhibited resorption of the graft material and enabled bone formation. In addition, the present study revealed a favourable effect of local pretreatment with $\mathrm{BP}$ solution at a dosage of $2 \mathrm{mg} \mathrm{ZA} / \mathrm{ml}$ autogeneous blood in the $\mathrm{AB}+\mathrm{ZA}$ and $\mathrm{AB}+\beta-\mathrm{TCP}+\mathrm{ZA}$ groups with regard to new bone formation, consistent with a previous report using a different BP (5).

In conclusion, the limited results obtained from the present study suggest that in the GBR procedure executed with a titanium rigid barrier, the use of local ZA with autogeneous blood and/or a graft material is more effective than the use of autogeneous blood or graft alone. It is proposed that this method may eliminate the use of bone graft materials in the treatment of bone defects in the future. In addition to this, taking into account the risks associated with systemic ZA use, further studies focusing on the local application of ZA with different graft materials and at different dosages are recommended to improve the successful development of GBR.

\section{References}

1. Buser D, Brägger U, Lang NP and Nyman S: Regeneration and enlargement of jaw bone using guided tissue regeneration. Clin Oral Implants Res 1: 22-32, 1990.

2. Schwarz F, Herten M, Ferrari D, Wieland M, Schmitz L, Engelhardt E and Becker J: Guided bone regeneration at dehiscence-type defects using biphasic hydroxyapatite+beta tricalcium phosphate (Bone Ceramic) or a collagen-coated natural bone mineral (BioOss Collagen): An immunohistochemical study in dogs. Int J Oral Maxillofac Surg 36: 1198-1206, 2007.

3. Ezirganli S, Polat S, Baris E, Tatar I and Celik HH: Comparative investigation of the effects of different materials used with a titanium barrier on new bone formation. Clin Oral Implants Res 24: 312-319, 2013.

4. Alam S, Ueki K, Nakagawa K, Marukawa K, Hashiba Y, Yamamoto E, Sakulsak N and Iseki S: Statin-induced bone morphogenetic protein (BMP) 2 expression during bone regeneration: An immunohistochemical study. Oral Surg Oral Med Oral Pathol Oral Radiol Endod 107: 22-29, 2009.

5. Toker H, Ozdemir H, Ozer H and Eren K: A comparative evaluation of the systemic and local alendronate treatment in synthetic bone graft: A histologic and histomorphometric study in a rat calvarial defect model. Oral Surg Oral Med Oral Pathol Oral Radiol 114 (5 Suppl): S146-S152, 2012.

6. Van Steenberghe D, Johansson C, Quirynen M, Molly L, Albrektsson T and Naert I: Bone augmentation by means of a stiff occlusive titanium barrier. Clin Oral Implants Res 14: 63-71, 2003.

7. Min S, Sato S, Saito M, Ebihara H, Arai Y and Ito K: Micro-computerized tomography analysis: Dynamics of bone augmentation within a titanium cap in rabbit calvarium. Oral Surg Oral Med Oral Pathol Oral Radiol Endod 106: 892-895, 2008.

8. Murai M, Sato S, Koshi R, Yokoyama K, Ikeda K, Narukawa M, Takayama T, Yoshinuma N and Ito K: Effects of the enamel matrix derivative and beta-tricalcium phosphate on bone augmentation within a titanium cap in rabbit calvarium. J Oral Sci 47: 209-217, 2005.

9. Molly L, Quirynen M, Michiels K and van Steenberghe D: Comparison between jaw bone augmentation by means of a stiff occlusive titanium membrane or an autologous hip graft: A retrospective clinical assessment. Clin Oral Implants Res 17: 481-487, 2006.

10. Doggrell SA: Clinical efficacy and safety of zoledronic acid in prostate and breast cancer. Expert Rev Anticancer Ther 9: 1211-1218, 2009.

11. Lipton A: The safety of zoledronic acid. Expert Opin Drug Saf 6: 305-313, 2007.

12. Abtahi J, Tengvall $P$ and Aspenberg P: Bisphosphonate coating might improve fixation of dental implants in the maxilla: A pilot study. Int J Oral Maxillofac Surg 39: 673-677, 2010. 
13. Friedl G, Radl R, Stihsen C, Rehak P, Aigner R and Windhager R The effect of a single infusion of zoledronic acid on early implant migration in total hip arthroplasty. A randomized, double-blind, controlled trial. J Bone Joint Surg Am 91: 274-281, 2009.

14. Abtahi J, Agholme F, Sandberg O and Aspenberg P: Effect of local vs. systemic bisphosphonate delivery on dental implant fixation in a model of osteonecrosis of the jaw. J Dent Res 92: 279-283, 2013

15. Ayan M, Dolanmaz D, Mihmanli A, Ayan A and Kürkcü M: The effect of systemically administrated zoledronic acid on the osseointegration of dental implants. Oral Dis 18: 802-808, 2012.

16. Back DA, Pauly S, Rommel L, Haas NP, Schmidmaier G, Wildemann B and Greiner SH: Effect of local zoledronate on implant osseointegration in a rat model. BMC Musculoskelet Disord 13: 42, 2012.

17. Ozdemir H, Ezirganli S, Isa Kara M, Mihmanli A and Baris E: Effects of platelet rich fibrin alone used with rigid titanium barrier. Arch Oral Biol 58: 537-544, 2013.

18. Greenstein $\mathrm{G}$ and Carpentieri JR: Utilization of d-PTFE barriers for post-extraction bone regeneration in preparation for dental implants. Compend Contin Educ Dent 36: 465-473, 2015.

19. Gardin C, Ricci S, Ferroni L, Guazzo R, Sbricoli L, De Benedictis G, Finotti L, Isola M, Bressan E and Zavan B: Decellularization and delipidation protocols of bovine bone and pericardium for bone grafting and guided bone regeneration procedures. PLoS One 10: e0132344, 2015.

20. Smiler D and Soltan M: The bone-grafting decision tree: A systematic methodology for achieving new bone. Implant Dent 15: 122-128, 2006.

21. Maréchal M, Luyten F, Nijs J, Postnov A, Schepers E and van Steenberghe D: Histomorphometry and micro-computed tomography of bone augmentation under a titanium membrane. Clin Oral Implants Res 16: 708-714, 2005.

22. Schmid J, Hämmerle $\mathrm{CH}$, Olah AJ and Lang NP: Membrane permeability is unnecessary for guided generation of new bone. An experimental study in the rabbit. Clin Oral Implants Res 5: 125-130, 1994

23. Martinez A, Balboa O, Gasamans I, Otero-Cepeda XL and Guitian F: Deproteinated bovine bone vs. beta-tricalcium phosphate as bone graft substitutes: Histomorphometric longitudinal study in the rabbit cranial vault. Clin Oral Implants Res 26: 623-632, 2015.
24. Daculsi G, Laboux O, Malard O and Weiss P: Current state of the art of biphasic calcium phosphate bioceramics. J Mater Sci Mater Med 14: 195-200, 2003.

25. Samavedi S, Whittington AR and Goldstein AS: Calcium phosphate ceramics in bone tissue engineering: A review of properties and their influence on cell behavior. Acta Biomater 9: 8037-8045, 2013.

26. Nishimura I, Shimizu Y and Ooya K: Effects of cortical bone perforation on experimental guided bone regeneration. Clin Oral Implants Res 15: 293-300, 2004.

27. Buser D, Dula K, Belser UC, Hirt HP and Berthold H: Localized ridge augmentation using guided bone regeneration. II. Surgical procedure in the mandible. Int J Periodontics Restorative Dent 15: 10-29, 1995.

28. Ito K, Minegishi T, Takayama T, Tamura T, Yamada $\mathrm{Y}$ and Sato S: Effects of ipriflavone on augmented bone using a guided bone regeneration procedure. Clin Oral Implants Res 18: 60-68, 2007.

29. Lundgren AK, Lundgren D, Hämmerle CH, Nyman S and Sennerby L: Influence of decortication of the donor bone on guided bone augmentation. An experimental study in the rabbit skull bone. Clin Oral Implants Res 11: 99-106, 2000.

30. Lundgren AK, Lundgren D, Wennerberg A, Hammerle CH and Nyman S: Influence of surface roughness of barrier walls on guided bone augmentation: Experimental study in rabbits. Clin Implant Dent Relat Res 1: 41-48, 1999.

31. Linde A, Thorén C, Dahlin C and Sandberg E: Creation of new bone by an osteopromotive membrane technique: An experimental study in rats. J Oral Maxillofac Surg 51: 892-897, 1993.

32. Rompen EH, Biewer R, Vanheusden A, Zahedi S and Nusgens B: The influence of cortical perforations and of space filling with peripheral blood on the kinetics of guided bone generation. A comparative histometric study in the rat. Clin Oral Implants Res 10: 85-94, 1999.

33. Schmid J, Wallkamm B, Hämmerle $\mathrm{CH}$, Gogolewski S and Lang NP: The significance of angiogenesis in guided bone regeneration. A case report of a rabbit experiment. Clin Oral Implants Res 8: 244-248, 1997.

34. Toker H, Ozdemir H, Ozer H and Eren K: Alendronate enhances osseous healing in a rat calvarial defect model. Arch Oral Biol 57: 1545-1550, 2012. 